\title{
Aus Alt mach Neu
}

\section{Liebe Leserin, lieber Leser,}

ist es nun richtig, dass die deutsche Bundesregierung oder ein Land generell den Kauf von Elektrofahrzeugen finanziell fördern soll? Diese Frage ist in den vergangenen Wochen sowohl in der Öffentlichkeit als auch in Fachkreisen hitzig diskutiert worden.

Wie bereits im Editorial der MTZ 4/2016 aufgegriffen, entscheidet jedoch nicht die Antriebsart - also Verbrennungsoder Elektromotor - darüber, ob sich Mobilität $\mathrm{CO}_{2}$-neutral und unabhängig von fossilen Energieträgern darstellen lässt. Denn sowohl Elektrizität als auch Kraftstoffe lassen sich entweder aus fossilen oder aber regenerativen Energieträgern zur Verfügung stellen.

Lade- und Entladeverluste einmal außen vor gelassen, sprechen die hohen Wirkungsgrade von bis zu $99 \%$ für E-Antriebe. Pro Verbrennungsmotor sind die hohe Reichweite sowie die großen Energiemengen, die pro Zeiteinheit getankt werden, zu nennen. Zudem können synthetische Kraftstoffe auf Wasserstoffbasis dabei helfen, überschüssige Elektrizität zu speichern. Frei nach dem Motto: Wandlungsverluste sind besser als stehende Windräder weil die Netzkapazität nicht ausreicht und elektrische Speicher fehlen.

Vor diesem Hintergrund sollte allen daran gelegen sein, die Diskussion über künftige Antriebe auch in der breiten Öffentlichkeit auf eine neue Grundlage zu stellen. Weder sind Verbrennungsmotoren „alt“ noch Elektromotoren „neu“. Historisch ist es sogar genau andersherum: Moritz Jacobi entwickelte in den 1830er-Jahren bereits eine E-Maschine, die sich zum Antrieb eines Boots eignete. Otto- und Dieselmotor folgten bekanntlich erst einige Jahrzehnte später.
Autohersteller und Zulieferer sind dran, die Lade- und Batterietechnik für Elektrofahrzeuge weiterzuentwickeln. Aber auch, die Effizienz von Verbrennungsmotoren weiter zu steigern. Es gilt, regenerativ erzeugte Energie mit allen denkbaren Antriebsarten bestmöglich zu nutzen. An Innovationen dazu mangelt es auf Seite der Verbrennungsmotoren nicht, wie unser Titelthema unter Beweis stellt. Sowohl Audi als auch Mazda zeigen, dass der bisherige Downsizing-Trend offenbar überdacht werden muss, um weitere Potenziale zu heben. Der japanische Hersteller zieht dabei sogar einen umfassenden Vergleich hinsichtlich der $\mathrm{CO}_{2}$-Gesamtbilanz im Vergleich zur Elektromobilität. Und ist davon überzeugt, dass der Verbrennungsmotor noch lange Bestand haben wird.

Herzliche Grüße und alles Gute,

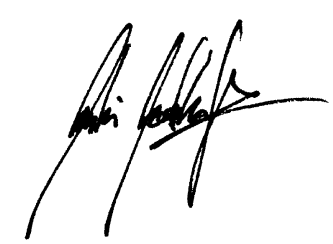

Dipl.-Journ. (FH) Martin Westerhoff Stellvertretender Chefredakteur

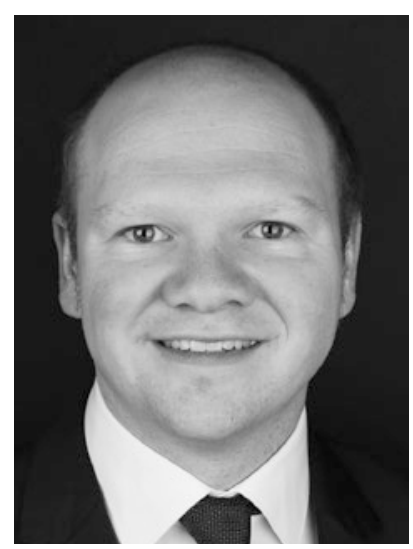

\section{Dienstleistungen für} Akustik \& Schwingungstechnik

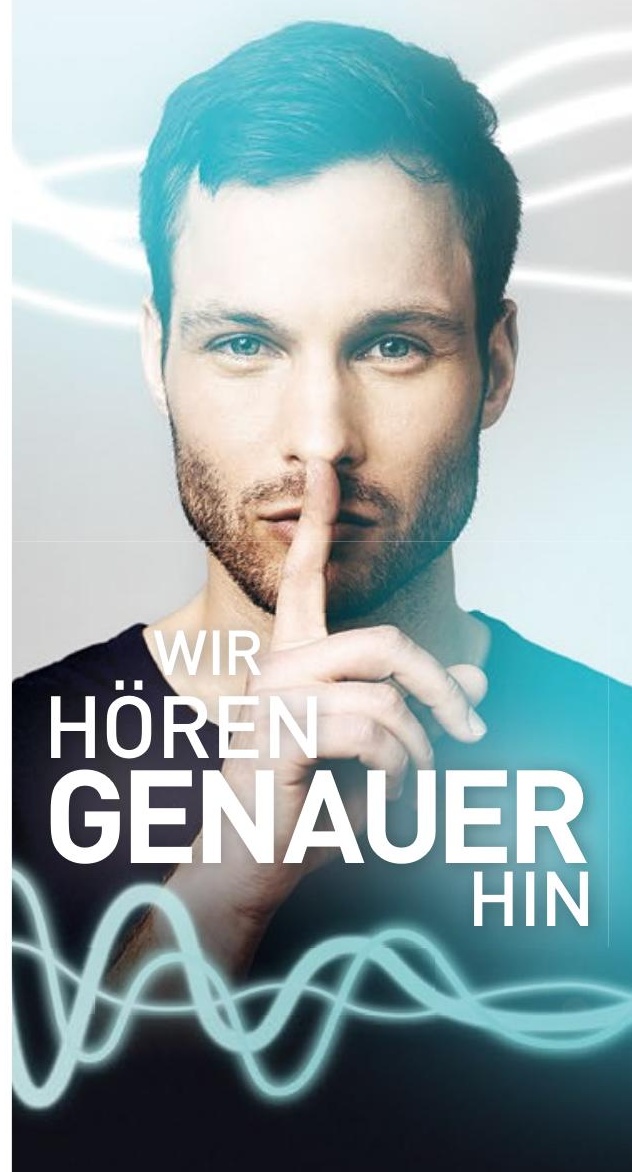

Als Experte für Vibroakustik wollen wir nur eines: Ihnen helfen, Ihr Produkt zu optimieren! Engineering, Messtechnik und modernste Prüfstände - alles aus einer Hand. Wir begleiten Ihren NVH-Entwicklungsprozess von der Komponente über den Motor bis hin zum Gesamtfahrzeug. Wir sind Ihr zuverlässiger, dynamischer und flexibler NVH-Dienstleister mit Sitz im Raum Stuttgart.

\section{D.A.S. GmbH}

Bertha-Benz-Str. 1

71120 Grafenau

$T+497033$ 69338-0

E infoldas-nvh.de 